\title{
RESISTÊNCIA AO CISALHAMENTO DE SOLOS E TALUDES VEGETADOS COM CAPIM VETIVER ${ }^{(1)}$
}

\author{
Michele Cristina Rufino Barbosa ${ }^{(2)}$ \& Hernani Mota de Lima ${ }^{(3)}$
}

\begin{abstract}
RESUMO
Taludes vegetados são mais resistentes contra movimentos de massa e erosão pela água. A vegetação contribui para a estabilidade do solo, principalmente pelo aumento da resistência ao cisalhamento por meio do reforço oferecido pelas raízes. As espécies vegetais que mais têm sido eficientes na estabilização de taludes instáveis são as gramíneas, pertencentes à família Poaceae. Um exemplar dessa família, capim vetiver (Chrysopogon zizanioides (L.) Roberty), tem se revelado muito eficaz nessa estabilização. Com o objetivo de avaliar a melhoria dos parâmetros de resistência ao cisalhamento oferecida ao solo pelas raízes do capim vetiver com o tempo de plantio, realizaram-se experimentos de cisalhamento direto por meio de amostras indeformadas de solo sem vegetação e cultivadas com capim vetiver na idade de um, dois, três e quatro anos de plantio. Também foram realizados experimentos de cisalhamento direto em talude do mesmo solo sem vegetação e com cobertura desse capim. Os resultados do ensaio de cisalhamento direto das amostras de talude de solo foram avaliados por três métodos de equilíbrio limite para verificação de um fator de segurança médio nos taludes. A partir dos ensaios de cisalhamento direto, determinaram-se os parâmetros de resistência ao cisalhamento (intercepto de coesão e ângulo de atrito interno), verificando que o capim vetiver proporcionou incremento de coesão aparente ao solo, sendo esse destacado após três anos de plantio do capim. Esse capim promoveu melhoria nos parâmetros de resistência com consequente elevação do fator de segurança de taludes e aumento da resistência ao cisalhamento de solos, o que auxiliou na estabilização de taludes em planos superficiais de ruptura.
\end{abstract}

Termos de indexação: cobertura vegetal, parâmetros de resistência ao cisalhamento, estabilização de taludes.

(1) Parte da tese de doutorado da primeira autora junto ao Programa de Pós-Graduação em Geotecnia da Universidade Federal de Ouro Preto - UFOP. Recebido para publicação em 23 de março de 2012 e aprovado em 29 de novembro de 2012.

${ }^{(2)}$ Doutoranda em Geotecnia pelo Núcleo de Geotecnia - NUGEO, Escola de Minas, Universidade Federal de Ouro Preto - UFOP, Campus Universitário. Morro do Cruzeiro s/n. CEP 35400-000 Ouro Preto (MG). E-mail: michele_crb@yahoo.com.br

(3) Professor Dr, Núcleo de Geotecnia (NUGEO), UFOP. E-mail: hernani.lima@ufop.br 


\title{
SUMMARY: SHEAR STRENGTH OF SOILS AND SLOPES COVERED WITH VETIVER
}

\begin{abstract}
Vegetated slopes are more resistant to mass movement and erosion by water. The vegetation contributes to the soil stability, especially by increasing the shear strength provided by roots. Plant species that have been most effective in stabilizing unstable slopes are the grasses, belonging to the family Gramineae. One specimen of this family, vetiver (Chrysopogon zizanioides (L.) Roberty), has proved very effective in slope stabilization. With the objective of evaluating the improvement of soil shear strength parameters at different times after vetiver planting, direct shear tests were carried out on soil without vegetation and soil with vetiver grass one, two, three and four years after planting. Direct shear tests were also carried out on the same slope soil without vegetation and covered with vetiver grass. The results of direct shear tests with soil slope samples were evaluated by three limit equilibrium methods to determine an average safety factor for the slopes. From the direct shear tests, the parameters cohesion and angle of internal friction were determined, which showed that vetiver grass increased apparent soil cohesion, which became significant three years after planting vetiver. The vetiver grass induced an improvement in resistance parameters with a consequent increase in the safety factor of slopes and increase in soil shear strength, contributing to slope stabilization of shallow ruptures.
\end{abstract}

Index terms: vegetation, shear strength parameters, slope stabilization.

\section{INTRODUÇÃO}

Uma das técnicas de bioengenharia para controle de erosão e estabilização de taludes é o uso da vegetação. As raízes da vegetação atuam como fibras que aumentam a resistência ao cisalhamento do solo.

Vários trabalhos estudaram a resistência ao cisalhamento de solos de acordo com o tipo de solo, grau de intemperismo e influência de minerais, podendo-se citar os estudos de Silva \& Cabeda (2005), Rocha et al. (2002), Silva \& Carvalho (2007) e Silva et al. (2004).

A carência de informações sobre os parâmetros de resistência ao cisalhamento dos solos e as suas relações com as demais propriedades dos solos tem limitado o desenvolvimento de técnicas que visem à estabilidade de taludes de terra (Rocha et al., 2002).

Para avaliar a contribuição da resistência ao cisalhamento do solo pelas raízes é necessário considerar a interação solo-raiz. Em um sistema desse tipo, as raízes podem ser tratadas como se fossem elementos flexíveis e elásticos, que, enterrados no solo, levam a um aumento da resistência contra eventuais escorregamentos nas encostas (Fiori \& Carmignani, 2009).

O capim vetiver (Chrysopogon zizanioides (L.) Roberty) tem revelado-se muito eficaz na estabilização de taludes. É uma planta aromática da família Proceae que chega a atingir $2 \mathrm{~m}$ de altura e suas raízes podem penetrar até $3 \mathrm{~m}$ de profundidade. É vastamente cultivado na Indonésia, Indias Ocidentais, África e Polinésia (Truong et al., 2008).

Esse capim pode crescer verticalmente em declives superiores a $150 \%$, aproximadamente $56^{\circ}$. O rápido crescimento desse capim faz com que esse seja considerado mais apropriado para estabilização de encostas em comparação com outras plantas. Outra característica que diferencia suas raízes das de outras plantas é o seu poder de penetração, pois suas raízes penetram inclusive em superfícies rochosas (Hengchaovanich, 1998).

Em um ensaio de cisalhamento direto em uma amostra indeformada de solo, Hengchaovanich \& Nilaweera (1996) constataram que a resistência ao cisalhamento do solo cultivado com capim vetiver com dois anos de plantio aumentou em $90 \%$, em relação ao solo sem cultivo.

As fibras radiculares aumentam a resistência ao cisalhamento do solo pela transferência das tensões cisalhantes que se desenvolvem na matriz do solo para as fibras, por meio do atrito na interface ao longo da extensão das fibras que estão fixas. Quando o cisalhamento ocorre, a fibra é deformada, o que causa um alongamento da fibra que mobiliza a resistência da fibra (Gray \& Sotir, 1996).

Os objetivos do estudo foram determinar os parâmetros de resistência, o intercepto de coesão e o ângulo de atrito interno de amostras do mesmo solo sem vegetação e com um, dois, três e quatro anos de plantio de capim vetiver para verificar a melhoria dos parâmetros de resistência de acordo com o tempo de plantio desse capim; e analisar os parâmetros de resistência em talude do mesmo solo sem cobertura vegetal e com cultivo de capim vetiver, com o intuito de investigar a eficiência dessa planta na estabilização de taludes.

\section{MATERIAL E MÉTODOS}

O local de estudo onde foram coletadas amostras indeformadas de solo está situado na área rural do município de Santana dos Montes, Estado de Minas 
Gerais. Esse local corresponde a uma das unidades da DEFLOR Bioengenharia, onde são cultivadas anualmente 1 milhão de mudas de capim vetiver, que são utilizadas principalmente nos trabalhos da empresa de obras de contenção de taludes.

Para a caracterização dos solos, os seguintes ensaios foram executados: granulometria NBR 7.181/ 84 (ABNT, 1984d); massa específica dos sólidos (densidade de partículas - Dp) NBR 6.508/84 (ABNT, 1984b); limite de liquidez (LL) NBR 6.459/84 (ABNT, 1984a); limite de plasticidade (LP) NBR 7.180/84 (ABNT, 1984c); e massa específica, umidade e teor de matéria orgânica (Embrapa, 1999). Realizaram-se esses ensaios no Laboratório de Geotecnia da Universidade Federal de Ouro Preto, que foram feitos em triplicatas em amostras deformadas de solo a uma profundidade de $0-30 \mathrm{~cm}$.

Para determinar os parâmetros de resistência do solo, adotou-se o método proposto por Chaulya et al. (2000), sendo realizados ensaios de cisalhamento direto em amostras indeformadas do mesmo solo sem cobertura vegetal e cobertas com capim vetiver após um, dois, três e quatro anos de plantio. Essas amostras foram coletadas em solos que não apresentavam inclinação. Para verificar os parâmetros de resistência em taludes, foram realizados ensaios de cisalhamento direto em um mesmo talude sem vegetação e com cultivo do capim com aproximadamente sete anos de plantio.

Para o ensaio de cisalhamento direto nas amostras de solo sem inclinação, foram retiradas amostras indeformadas a uma profundidade de 0-60 $\mathrm{cm}$ da superfície. Já para o ensaio de cisalhamento direto nas amostras de taludes, retiraram-se amostras indeformadas de 30-90 $\mathrm{cm}$ de profundidade. Essa variação na profundidade ocorreu em razão do grande número de raízes encontradas próximas à superfície do talude de solo com plantio de capim vetiver, sendo inviável a realização do ensaio de cisalhamento direto por causa da dificuldade de moldagem do corpo de prova.

As amostras indeformadas foram coletadas, de acordo com a Norma NBR 9.604/86, em triplicatas. Coletaram-se três amostras de solo sem cobertura vegetal; três de solo com um ano de plantio de capim vetiver; três de solo com dois anos de plantio desse capim; três de solo com três anos de plantio do capim; três de solo com quatro anos de plantio do capim; três de solo de talude sem cobertura vegetal; e três de solo do mesmo talude com cultivo de capim vetiver. Um total de 21 amostras indeformadas foram analisadas.

Os ensaios de cisalhamento direto foram realizados, de acordo com a ASTM D3080 (ASTM, 2004). As amostras indeformadas de solo foram previamente moldadas em uma caixa metálica bipartida de seção transversal quadrada de dimensões de 100 × 100 × 20 $\mathrm{mm}$. Colocaram-se pedras porosas associadas a placas metálicas e ranhuradas (para evitar o deslizamento do solo em relação às pedras porosas) no topo e na base do corpo de prova para permitir a livre drenagem da água intersticial durante os ensaios. Feito isso, as amostras foram postas na prensa de cisalhamento direto, modelo digital da marca Contenco, e foram totalmente imersas em água por um período de $24 \mathrm{~h}$ para realizar o ensaio em uma condição desfavorável, na presença de água.

Os ensaios de cisalhamento direto foram feitos de forma drenada. A velocidade que foi adotada no ensaio foi determinada previamente, de modo a garantir a dissipação das pressões neutras geradas. Para a estimativa da velocidade de cisalhamento, foram feitos ensaios testes em cada um dos grupos de amostras, sendo a velocidade do ensaio de cisalhamento direto obtida de acordo com Head (1994), por meio da equação 1:

$$
v=D_{f} \cdot H_{0} \cdot \frac{1}{100 \cdot t_{f}}
$$

em que $v=$ velocidade usada no ensaio de cisalhamento direto, $D_{f}=$ deformação específica da resistência de pico, $H_{0}=$ altura inicial do corpo de prova e $t_{\mathrm{f}}=$ tempo para atingir a resistência de pico.

A deformação específica para atingir a resistência de pico é função do estado de compacidade do material ensaiado. Para os ensaios de cisalhamento direto convencional em condições drenadas e sob dupla fronteira drenante, o tempo necessário para se atingir a condição de ruptura $\left(\mathrm{t}_{\mathrm{f}}\right)$ é obtido pela equação 2 :

$$
t_{f}=14 \cdot t_{100}
$$

em que $t_{100}$ é o valor do tempo correspondente a $100 \%$ dos recalques induzidos pelos acréscimos de carga.

Os parâmetros intercepto de coesão e ângulo de atrito interno foram determinados conforme Lambe \& Whitman (1951) e obtidos por meio do critério de ruptura de Mohr-Coulomb, de acordo com a equação 3 , quando as tensões normais correspondentes a 50, 100,200 e $400 \mathrm{kPa}$ foram aplicadas às amostras indeformadas na prensa de cisalhamento direto.

$$
\tau_{f}=c+\sigma \tan \phi
$$

em que $\tau_{\mathrm{f}}=$ resistência ao cisalhamento $(\mathrm{kPa}), \mathrm{c}=$ intercepto de coesão do solo ( $\mathrm{kPa}), \sigma=$ tensão normal $(\mathrm{kPa})$ e $\tan \phi=$ coeficiente de atrito, cujo arco tangente é o ângulo de atrito interno do solo.

Para determinar o coeficiente de segurança do talude, foram realizadas simulações, considerando o talude com apenas um tipo de solo em uma inclinação de $45^{\circ}$, o que é válido em razão de as raízes do capim vetiver atuarem no aumento da resistência nos planos superficiais de ruptura até à profundidade de aproximadamente $1,5 \mathrm{~m}$ e em taludes de inclinação de até $56^{\circ}$. A análise foi realizada considerando uma ruptura global do talude passando pela camada mais superficial, ou seja, a camada mais propícia a ocorrer instabilidade.

As análises de estabilidade foram feitas utilizando o software SLOPE/W da Geoslope pelo método do 
equilíbrio limite, sendo usados os métodos de Bishop, Janbu e Morgenstern-Price, que foram escolhidos para determinar um fator de segurança médio. Bishop é muito usado na prática e recomendado para projetos simples; Morgenstern-Price, indicado para estudos preliminares em projetos simples de taludes homogêneos com inclinação superior a $27^{0}$; e Janbu, aplicado também para solos homogêneos e tem uma grande aplicação (Gerscovich, 2012).

\section{RESULTADOS E DISCUSSÃO}

No quadro 1, são apresentados os resultados dos ensaios de caracterização física do solo.

Os valores de densidade do solo natural (D) foram em torno de $2,09 \mathrm{Mg} \mathrm{m}^{-3}$, considerando valores comuns para solos predominantemente arenosos; os valores de D também são de solos arenosos. Somente o solo sem vegetação e o talude sem vegetação encontramse fora dos padrões. O teor de umidade das amostras diminuiu com o tempo de plantio do capim vetiver, verificando preliminarmente aumento de coesão aparente, pois essa se eleva com a diminuição da umidade (Das, 2007).

Em relação aos valores obtidos de limite de plasticidade, limite de liquidez e índice de plasticidade houve pequena variação para cada grupo analisado, pois todas as amostras se enquadram no mesmo tipo de solo.

Na figura 1, está evidenciado o resultado do ensaio de análise granulométrica, em que há apenas uma curva no gráfico, pois o solo do local de coleta de amostras e o do talude apresentaram as mesmas características, o que corresponde a um mesmo tipo de solo. Os resultados mostram que o solo correspondia a um areno-siltoso, de acordo com a classificação ABNT e o Sistema Unificado.

Em solos predominantemente arenosos, a resistência ao cisalhamento depende basicamente do atrito entre as partículas, enquanto em solos argilosos essa depende não só do atrito entre partículas como também da coesão do solo (Silva \& Carvalho, 2007).

O teor da matéria orgânica das amostras analisadas é apresentado no quadro 2 .

Observou-se que o teor de matéria orgânica (MO) (Quadro 2) aumentou com o tempo de plantio do capim vetiver, sendo encontrado o maior valor de MO nas amostras de talude de solo com aproximadamente sete anos de plantio de capim vetiver. Verificou-se assim maior presença de raízes com o aumento do tempo de plantio de capim vetiver.

$\mathrm{Na}$ literatura, há divergência de resultados em relação aos teores de $\mathrm{MO}$ e análise da resistência ao cisalhamento do solo, evidenciando situações em que maiores teores de MO são acompanhados de diminuição da resistência ao cisalhamento do solo (Ohu et al., 1985; Ohu et al., 1986) e outras em que essa aumenta (Davies, 1985; Ekwue, 1990; Braida, 2004). Provavelmente, essas diferenças são em razão da origem da MO (Ekwue, 1990), do tempo decorrido após a incorporação da MO e do teor de água no solo (Davies, 1985; Zhang \& Hartge, 1990).

A matéria orgânica atua sobre os parâmetros do cisalhamento de diferentes formas. Basicamente, esperou-se aumento da coesão entre as partículas do solo, resultante da elevação da força das ligações e, ou, do estabelecimento de novas ligações entre essas, seja pelas características físicas e químicas das moléculas orgânicas, seja em razão de enlaces de partículas produzidas por filamentos orgânicos como as raízes (Soane, 1990).

A matéria orgânica aumenta a resistência do solo à compressão, quando predominam os efeitos de aumento dos parâmetros de cisalhamento, aumento da tensão capilar com aumento da coesão aparente, diminuição do efeito da água na redução da fricção entre partículas, redução da densidade por efeito de diluição e aumento da elasticidade do solo (Braida et al., 2010).

Nos ensaios de cisalhamento direto, os valores de velocidade de ensaio seguindo os estudos de Head

Quadro 1. Valores de limite de liquidez (LL), limite de plasticidade (LP), índice de plasticidade (IP), densidade de partículas (Dp), densidade do solo natural (D), densidade do solo (Ds) e umidade gravimétrica (U) obtidos nos ensaios de caracterização física

\begin{tabular}{|c|c|c|c|c|c|c|c|}
\hline Solo & $\mathbf{L L}$ & $\mathbf{L P}$ & IP & $\mathbf{D}_{\mathbf{p}}$ & $\mathbf{D}$ & Ds & $\mathbf{U}$ \\
\hline & & & - & - & $\mathrm{Mg} \mathrm{m}^{-3}$ & & $\%$ \\
\hline Sem vegetação & 19 & 9 & 10 & 2,64 & 2,04 & 1,54 & 32 \\
\hline Um ano de plantio de capim vetiver & 20 & 11 & 9 & 2,66 & 2,08 & 1,64 & 27 \\
\hline Dois anos de plantio de capim vetiver & 21 & 12 & 9 & 2,69 & 2,10 & 1,68 & 25 \\
\hline Três anos de plantio de capim vetiver & 21 & 12 & 9 & 2,74 & 2,11 & 1,77 & 19 \\
\hline Quatro anos de plantio de capim vetiver & 22 & 13 & 9 & 2,76 & 2,11 & 1,80 & 17,5 \\
\hline Talude sem vegetação & 19 & 10 & 9 & 2,63 & 2,06 & 1,61 & 28,5 \\
\hline Talude com sete anos de plantio de capim vetiver & 23 & 11 & 12 & 2,77 & 2,12 & 1,73 & 23 \\
\hline
\end{tabular}




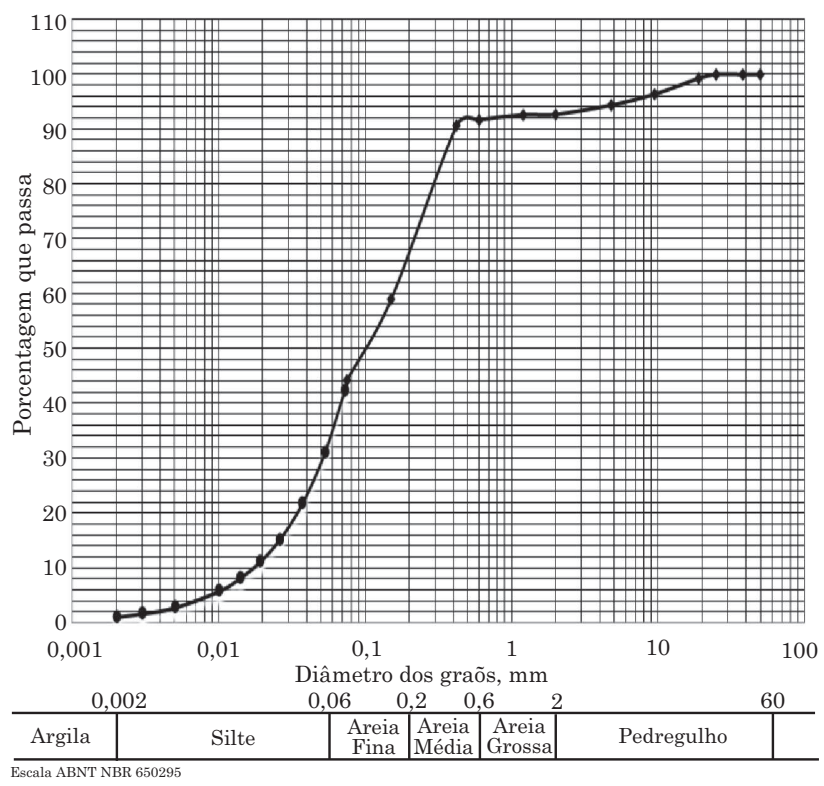

Figura 1. Resultado da granulometria conjunta.

Quadro 2. Teor de matéria orgânica (MO) das amostras de solo

\begin{tabular}{lc}
\hline \multicolumn{1}{c}{ Solo } & MO \\
\hline & $\%$ \\
Sem vegetação & $0-60 \mathrm{~cm}$ \\
Um ano de plantio de capim vetiver & 10,1 \\
Dois anos de plantio de capim vetiver & 15,9 \\
Três anos de plantio de capim vetiver & 17,5 \\
Quatro anos de plantio de capim vetiver & 21,9 \\
& 22,2 \\
Talude de solo sem vegetação & $30-90 \mathrm{~cm}$ \\
Talude com aplicação de capim vetiver & 9,1 \\
\hline
\end{tabular}

(1994) variaram entre 0,04 e $0,06 \mathrm{~mm} \mathrm{~min}^{-1}$. No quadro 3 , são apresentados os resultados do ensaio de cisalhamento direto em razão dos parâmetros de resistência (intercepto de coesão e ângulo de atrito interno) do solo sem cobertura vegetal e com um, dois, três e quatro anos de cultivo de capim vetiver.

Os resultados dos ensaios de cisalhamento direto (Quadro 3) evidenciam variação pequena em relação ao ângulo de atrito interno. Já a coesão aparente apresenta aumento considerável (aproximadamente $167 \%$ ) entre os resultados do solo com dois anos de plantio de capim vetiver e três anos de plantio desse mesmo capim. Pode-se considerar que o capim oferece incremento de coesão aparente ao solo a partir de três anos de plantio. Esse aumento de coesão pode estar relacionado à elevação do teor de $\mathrm{MO}$ do solo, pois essa oferece acréscimo de resistência ao cisalhamento quando ocorre aumento dos parâmetros de resistência.
Quadro 3. Parâmetros de resistência ao cisalhamento do solo nas variações estudadas e do talude de solo sem e com plantio do capim vetiver

\begin{tabular}{|c|c|c|}
\hline Solo/Talude & $\begin{array}{c}\text { Ângulo } \\
\text { de atrito } \\
\text { interno }\end{array}$ & $\begin{array}{r}\text { Intercepto } \\
\text { de coesão }\end{array}$ \\
\hline & & $\mathrm{kPa}$ \\
\hline Sem vegetação & $14,6^{0}$ & 23,4 \\
\hline Um ano de plantio de capim vetiver & $14,6^{0}$ & 23,8 \\
\hline Dois anos de plantio de capim vetiver & $14,8^{0}$ & 25,9 \\
\hline Três anos de plantio de capim vetiver & $16,9^{0}$ & 68,9 \\
\hline Quatro anos de plantio de capim vetiver & $19,9^{0}$ & 73,5 \\
\hline \multicolumn{3}{|l|}{ Talude de solo } \\
\hline Sem plantio do capim vetiver & $18,5^{0}$ & 28,4 \\
\hline Com plantio do capim vetiver & $18,9^{0}$ & 74,5 \\
\hline
\end{tabular}

Evidencia-se, na figura 2, a variação do intercepto de coesão ao longo do tempo de plantio do capim vetiver. Observou-se que o capim só teve efeito no intercepto de coesão (Quadro 3 e Figura 2) e no ângulo de atrito interno (Quadro 3) a partir do segundo ano de plantio, promovendo maior resistência ao cisalhamento do solo sob plantio desse capim.

A principal contribuição das raízes ao solo, no que diz respeito à resistência ao cisalhamento, é o incremento de uma coesão aparente ao solo. Essa coesão aparente auxilia na estabilidade com relação a rupturas rasas em solos arenosos com pouca ou sem nenhuma coesão intrínseca (Lemes, 2001). Sendo assim, as raízes do capim vetiver oferecem uma parcela de coesão aparente ao solo, o que auxilia no processo de estabilidade do solo.

Na figura 3, são apresentadas as curvas de tensões cisalhantes versus deslocamentos horizontais obtidas nos ensaios de cisalhamento direto das amostras coletadas no talude sem a cobertura vegetal. Nessa figura, observa-se que com o aumento da tensão normal ocorreu aumento na tensão cisalhante com redução no deslocamento horizontal. Em adição, o material apresentou comportamento frágil, pois após a tensão de pico elevado houve queda significativa nas curvas tensões cisalhantes versus deslocamentos horizontais, principalmente para os valores de tensões normais de 100 e $200 \mathrm{kPa}$, apresentando diferença acentuada entre a tensão de pico e a residual.

As curvas de tensão cisalhante versus tensão normal, que corresponde à envoltória de ruptura em que foram obtidos os parâmetros de resistência do talude sem a cobertura do capim vetiver são apresentadas na figura 4.

Na figura 5, são apresentadas as curvas de tensões cisalhantes versus deslocamentos horizontais obtidas nos ensaios de cisalhamento direto das amostras coletadas nos taludes com plantio do capim vetiver. 


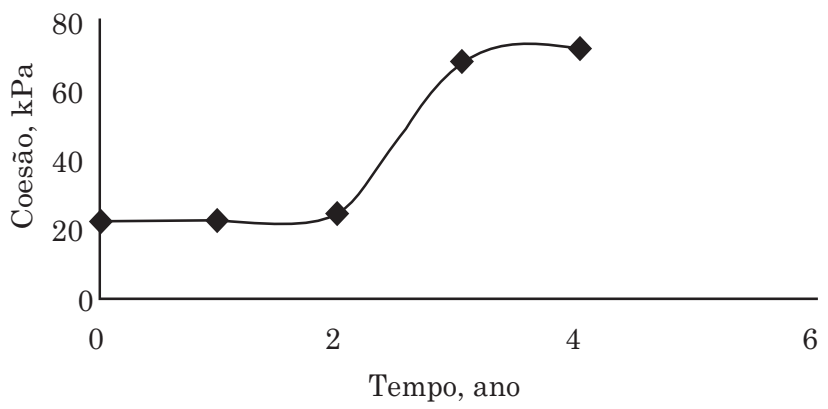

Figura 2. Variação do intercepto de coesão ao longo do tempo de plantio do capim vetiver.

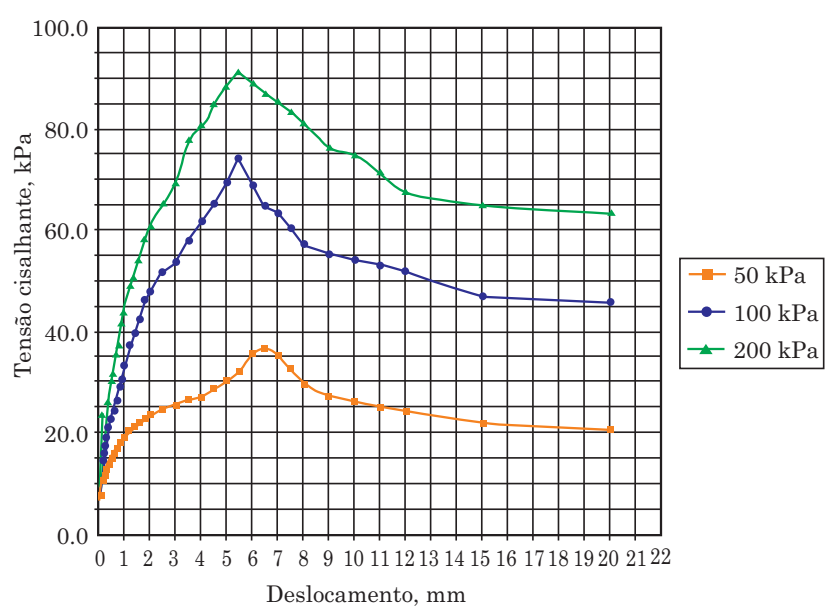

Figura 3. Tensão cisalhante $v$ s deslocamento horizontal para as amostra do talude sem cobertura do capim vetiver.

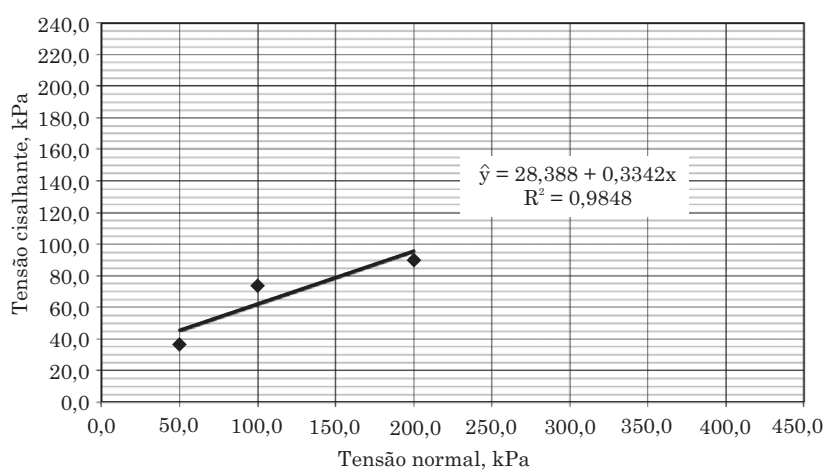

Figura 4. Envoltória de ruptura do talude sem plantio do capim vetiver.

Nessa figura, estão representados quatro ensaios com valores de tensão normal correspondentes a 50, 100, 200 e $400 \mathrm{kPa}$. O ensaio foi realizado para a tensão de $400 \mathrm{kPa}$ pelo fato de os ensaios de cisalhamento direto realizados com as tensões de 50, 100 e 200 $\mathrm{kPa}$ não terem apresentado tensão de pico bem caracterizada.

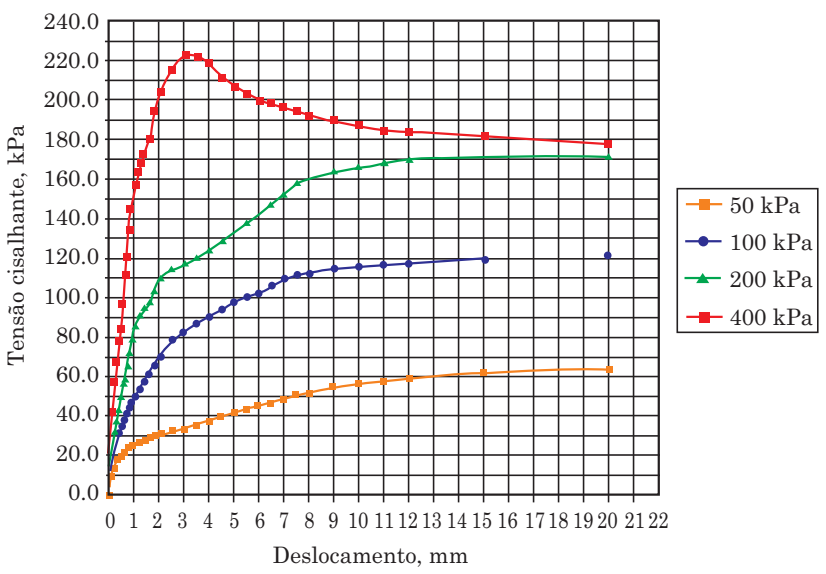

Figura 5. Tensão cisalhante $x$ deslocamento horizontal para as amostras do talude com sete anos de plantio do capim vetiver.

Observa-se, na figura 5, que com o aumento da tensão normal ocorreu elevação na tensão cisalhante, porém não se verificou redução no deslocamento horizontal para as tensões aplicadas de 50, 100 e 200 $\mathrm{kPa}$, sendo essa diminuição observada apenas na tensão de $400 \mathrm{kPa}$.

A curva referente à tensão de $400 \mathrm{kPa}$ (Figura 5) apresentou comportamento similar às apresentadas no ensaio de cisalhamento realizado com amostras do mesmo solo do talude sem o plantio do capim vetiver, observando-se tensão de pico bem característica. As demais curvas da figura 5 apresentaram comportamento dúctil, em que não se observou diferença acentuada entre a tensão de pico e a residual.

$\mathrm{Na}$ figura 6, evidenciam-se as curvas tensão cisalhante versus tensão normal, que correspondem à envoltória de ruptura para os ensaios da amostra de talude com plantio do capim vetiver.

Os parâmetros de resistência ao cisalhamento de Mohr-Coulomb para as amostras do talude sem cobertura vegetal e para as amostras do talude com cultivo de capim vetiver são apresentados no quadro 3. Esses parâmetros de resistência, que são o ângulo de atrito interno (inclinação da reta) e o intercepto de coesão (valor da tensão cisalhante quando a reta corta o eixo das tensões cisalhantes), foram obtidos a partir das figuras 4 e 6 . Observou-se, no quadro 3, aumento da coesão e do ângulo de atrito interno do solo do talude com plantio de capim vetiver, o que ficou evidenciado aumento da resistência ao cisalhamento de solos sob plantio do capim vetiver, pois os valores de ângulo de atrito e coesão aumentaram. Destacou-se o valor da coesão que aumentou em $174 \%$, enquanto o ângulo de atrito teve elevação irrelevante.

Na figura 7, é apresentada a análise de estabilidade de taludes, considerando a ruptura global de um talude com a inclinação de $45^{\circ}$ para os parâmetros de resistência obtidos no ensaio de cisalhamento direto (Quadro 3). Obtiveram-se os fatores de segurança para 
o talude sem cobertura vegetal e com cobertura de capim vetiver.

Observa-se, na figura 7, que os planos de ruptura são maiores para as simulações de talude sem plantio de capim vetiver do que os apresentados para os taludes vegetados com capim vetiver.

No quadro 4, são apresentados os coeficientes de segurança obtidos de acordo com cada método do equilíbrio limite utilizado neste estudo, observando uma variação mínima dos valores de fator de segurança entre os métodos analisados. Notou-se que

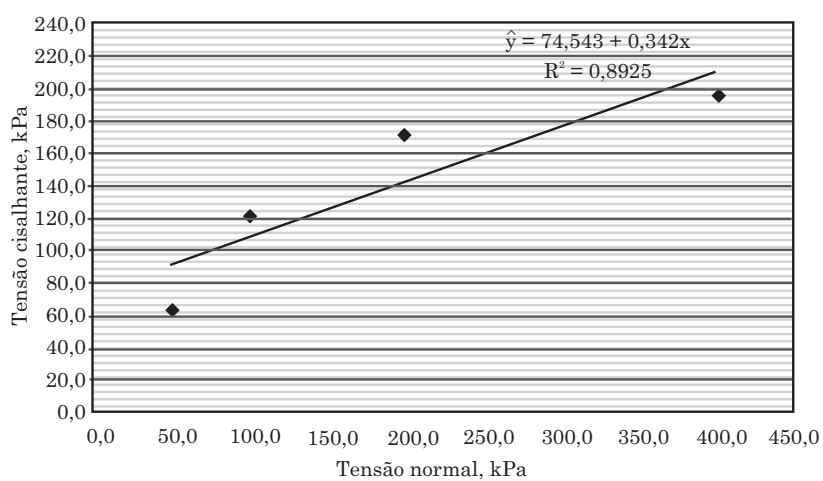

Figura 6. Envoltória de ruptura do talude com sete anos de plantio do capim vetiver.

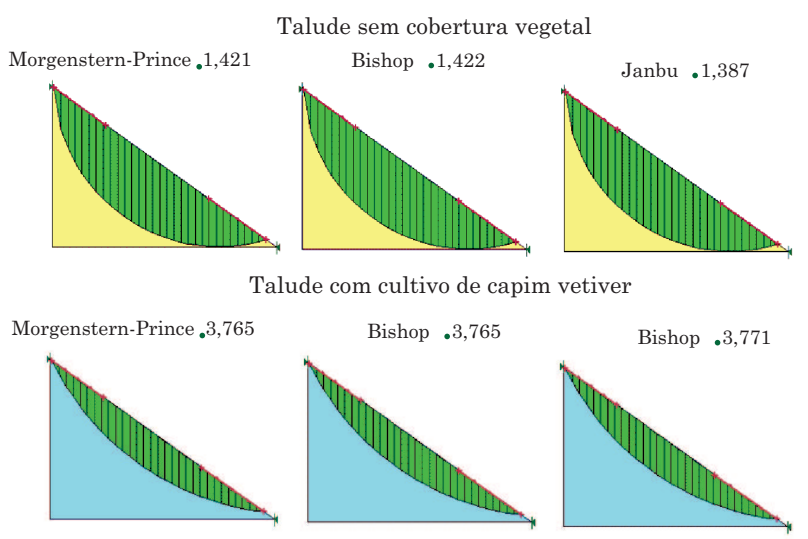

Figura 7. Análise da estabilidade de taludes sem cobertura vegetal e com sete anos de plantio do capim vetiver.

Quadro 4. Coeficientes de segurança do talude sem cobertura vegetal e com cobertura de capim vetiver

\begin{tabular}{lccc}
\hline Talude & $\begin{array}{c}\text { Morgenstern- } \\
\text { Price }\end{array}$ & Bishop & Janbu \\
\hline $\begin{array}{l}\text { Sem cobertura vegetal } \\
\text { Com cobertura de }\end{array}$ & 1,421 & 1,422 & 1,387 \\
capim vetiver & 3,765 & 3,765 & 3,771 \\
\hline
\end{tabular}

os valores dos coeficientes de segurança são sempre maiores para o talude com cobertura de capim vetiver, com aumento de aproximadamente $167 \%$ em relação ao fator de segurança do talude sem vegetação, o que indicou estabilização do talude com o cultivo do capim vetiver, prevenindo que os planos de instabilidade sejam inferiores a $1,5 \mathrm{~m}$, que equivalem os planos mais propícios a ocorrerem rupturas.

\section{CONCLUSÕES}

1. Os parâmetros de resistência ao cisalhamento de solos (intercepto de coesão e ângulo de atrito interno) aumentaram com o tempo de plantio do capim vetiver, destacando o valor da coesão aparente após três anos de cultivo desse capim.

2. O capim vetiver auxilia na estabilização de taludes, pois proporciona incremento de coesão aparente ao solo e aumenta o fator de segurança dos taludes.

\section{AGRADECIMENTO}

À DEFLOR Bioengenharia, pelas amostras de solo cedidas para realizar este estudo e pelo apoio prestado.

\section{LITERATURA CITADA}

ASSOCIAÇÃO BRASILEIRA DE NORMAS TÉCNICAS ABNT. Determinação do Limite de Liquidez, NBR 6459. Rio de Janeiro, 1984a.

ASSOCIAÇÃO BRASILEIRA DE NORMAS TÉCNICAS ABNT. Grãos de solo que passam na peneira de 4,8 mm: Determinação da massa específica, NBR 6508. Rio de Janeiro, 1984b.

ASSOCIAÇÃO BRASILEIRA DE NORMAS TÉCNICAS ABNT. Determinação do Limite de Plasticidade, NBR 7180. Rio de Janeiro, 1984c.

ASSOCIAÇÃO BRASILEIRA DE NORMAS TÉCNICAS ABNT. Análise Granulométrica, NBR 7181. Rio de Janeiro, 1984d.

AMERICAN SOCIETY FOR TESTING AND MATERIALS ASTM. Standard Test Method for Direct Shear Test of Soils Under Consolidated Drained Conditions, D3080, 2004.

BRAIDA, J.A. Matéria orgânica e resíduos vegetais na superfície do solo e suas relações com o comportamento mecânico do solo sob plantio direto. Santa Maria, Universidade Federal de Santa Maria, 2004. 126p. (Tese de Doutorado)

BRAIDA, J.A.; REICHERT, J.M.; DALVAN, J.; REINERT, D.J. \& VEIGA, M. Teor de carbono orgânico e a susceptibilidade à compactação de um nitossolo e um argissolo. R. Bras. Eng. Agríc. Amb., 14:131-139, 2010. 
CHAULYA, S.K.; SINGH, R.S.; CHAKRABORTY, M.K. \& SRIVASTAVA, B.K. Quantification of stability improvement of a dump through biological reclamation. Geotechn. Geol. Eng., 18:193-207, 2000.

DAS, B.M. Fundamentos de engenharia geotécnica. 6.ed. São Paulo, Thomson Learning, 2007. 562p.

DAVIES, P. Influence of organic matter content, moisture status and time after reworking on soil shear strength. J. Soil Sci., 36:299-306.1985.

EKWUE, E.I. Organic matter effects on soil strength properties. Soil Tillage Res., 16:289-297, 1990.

EMPRESA BRASILEIRA DE PESQUISA AGROPECUÁRIA . EMBRAPA. Sistema brasileiro de classificação de solos. Brasília, 1999. 412p.

FIORI, A.P. \& CARMIGNANI, L. Fundamentos de mecânica dos solos e das rochas, aplicações na estabilidade de taludes. 2.ed. Curitiba, Universidade Federal do Paraná, 2009. 602p.

GRAY, D.H. \& SOTIR, R.B. Biotechnical and soil bioengineering slope stabilization: A practical guide for erosion control. New York, John Wiley \& Sons, 1996. 378p.

GERSCOVICH, D. Estabilidade de taludes. Rio de Janeiro, Oficina de Textos, 2012. 168p.

HEAD, K.H. Manual of soil laboratory testing. 2.ed. New York, John Wiley \& Sons, 1994. 440p.

HENGCHAOVANICH, D. Vetiver grass for slope stabilization and erosion control. 2.ed. Bangkok, Pacific Rim Vetiver Network,1998. 28p.

HENGCHAOVANICH, D. \& NILAWEERA, N. An assessment of strength properties of vetiver grass roots in relation to slope stabilization. In: INTERNATIONAL CONFERENCE ON VETIVER, 1., Bangkok, 1996. Anais... Bangkok, 1996. CD ROM.

LAMBE, T.W. \& WHITMAN, R.V. Soil testings for engineers. 2.ed. New York, John Wiley, 1951. 165p.
LEMES, M.R.T. Revisão dos efeitos da vegetação em taludes. Porto Alegre, Universidade Federal do Rio Grande do Sul, 2001. 140p. (Dissertação de Mestrado)

OHU, O.J.; RAGHAVAN, G.S.V. \& McKYES, E. Peat moss effect on the physical and hydraulic characteristics of compacted soils. Trans. Am. Sci. Agric. Eng., 28:420-424. 1985.

OHU, O.J.; RAGHAVAN, G.S.V.; McKYES, E. \& MEHUYS, G. Shear strength prediction of soils with varying added organic matter contents. Trans. Am. Sci. Agric. Eng., 29:351-355. 1986.

ROCHA, W.W.; DIAS JUNIOR, M.S.; LIMA, J.M.; MIRANDA, E.E.V. \& SILVA, A.R. Resistência ao cisalhamento e grau de intemperismo de cinco solos na região de Lavras (MG). R. Bras. Ci. Solo, 26:297-303, 2002.

SILVA, R.B.; DIAS JÚNIOR, M.S.; SANTOS, F.L. \& FRANZ, C.A.B. Resistência ao cisalhamento de um Latossolo sob diferentes uso e manejo. R. Bras. Ci. Solo, 28:165-173, 2004.

SILVA, A.J.N. \& CABEDA, M.S.V. Influência de diferentes sistemas de uso e manejo na coesão, resistência ao cisalhamento e óxidos de $\mathrm{Fe}$, Si e $\mathrm{Al}$ em solo de tabuleiro costeiro de Alagoas. R. Bras. Ci. Solo, 29:447-457, 2005.

SILVA, A.J.N. \& CARVALHO, F.G. Coesão e resistência ao cisalhamento relacionadas a atributos físicos e químicos de um Latossolo Amarelo de tabuleiro costeiro. R. Bras. Ci. Solo, 31:853-862, 2007.

SOANE, B.D. The role of organic matter in soil compactability: A review of some practical aspects. Soil Tillage Res., 16:179-201, 1990.

TRUONG, P.; VAN, T.T. \& PINNERS, E. Vetiver system applications: Technical reference manual 2.ed. Vietnam, The Vetiver Network International, 2008. 127p.

ZHANG, H.Q. \& HARTGE, K.H. Cohesion in unsaturated sandy soils and the influence of organic matter. Soil Technol., 3:311-326, 1990. 